\title{
Alkaline Phosphatase Isoenzyme Measurement
}

National Cancer Institute

\section{Source}

National Cancer Institute. Alkaline Phosphatase Isoenzyme Measurement. NCI

Thesaurus. Code C139091.

The determination of the amount of alkaline phosphatase isoenzyme present in a sample. 